\title{
LOS EXILIOS DE CLEMENTE AIRÓ. EL ROL DE UN EDITOR HETERODOXO EN LA REVISTA DE ARTES Y LETRAS ESPIRAL DE COLOMBIA (1944-1975)*
}

\author{
ALBERTO BEJARANO \\ Instituto Caro y Cuervo, Colombia \\ alberto.bejarano@caroycuervo.gov.co
}

\section{RESUMEN}

En nuestro artículo estudiamos el rol de Clemente Airó como editor en la revista colombiana de artes y letras Espiral (1944-1975). Nos preguntamos por su relación con otras definiciones de canon artístico en la época, comparado con la crítica argentina Marta Traba.

PALABRAS CLAVE: Edición en Colombia, Artes plásticas, Revistas de arte, Airó, Traba

\section{THE EXIL OF CLEMENTE AIRÓ IN THE MAGAZIN OF ARTS AND LITTERATURE, ESPIRAL, IN COLOMBIA (1944-1975)}

\section{ABSTRACT}

Our purpose in this article is to study the figure of Clemente Airó as publisher of Espiral, a Colombian magazine about arts and literature (1944-1975). Our question is how he built another kind of artistic definition in comparison with Marta Traba's approach.

KeYWORDS: Edition in Colombia, Plastic arts, Art magazins, Airó, Traba

\section{INTRODUCCIÓN}

Al finalizar la guerra civil española, fueron numerosos los exiliados que llegaron a Colombia, si bien no puede compararse la cifra con los que llegaron a Argentina o México, principales destinos de emigración. Aún así, debería mirarse su impacto no desde el punto de vista cuantitativo, sino desde los singulares aportes a la cultura y a las artes de quienes se instalaron en Colombia, por un tiempo o definitivamente. Importantes familias, en especial de origen catalán como los Roda, Fornaguera, Trias, Prat, entre otros, contribuyeron al desarrollo del país en diferentes áreas. ${ }^{1}$ Los exiliados españoles en Colombia se constituyeron como una colonia fuerte que conservó muchas tradiciones, sin que ello significara que todos fueran republicanos. Se dio por ejemplo el caso de familias de origen español de dos bandos distintos unidos por alianzas matrimoniales como los Fornaguera y Carulla. En cuanto al caso que nos interesa, la figura de Clemente Airó, es quizá la más significativa del exilio español en Colombia, junto al

\footnotetext{
* Este artículo hace parte del Proyecto "El exilio en espiral de Clemente Airó", financiado por el Instituto Caro y Cuervo (2017-2018).

1 Para profundizar en este tema ver, Vejarano, Fernán, Españoles en Colombia Siglo XX, Ed. Fundación españoles en Colombia, Bogotá, 2004.
} 
pedagogo Miguel Fornaguera de quien solo recientemente se ha compilado su archivo, el cual reposa en la Biblioteca de la Universidad Javeriana.

\section{Airó y la Revista ESPIRAL}

"Se es siempre aprendiz y yo jamás me he considerado un maestro. Mi condición de explorador inalcanzable no lo cambio por nada en el mundo. ¿Orgullo? No. Cada vez que debo empezar un poema o un artículo, una carta o una simple papeleta de saludo, me encuentro ante un cúmulo de dificultades que dejan perplejo. Escribir es descubrir. Poetizar es descubrir. El poema es un test que yo me propongo y mi obra más lograda es un porcentaje de éxito". Luis Vidales

Partimos de este epígrafe de Luis Vidales, -poeta e intelectual colombiano, destacada personalidad de las letras colombianas y latinoamericanas en el siglo XX. El epígrafe nos es útil para señalar la identidad de la revista Espiral en cuanto al contraste que significa frente a la figura de Marta Traba, en especial en lo que se refiere a otras historias posibles del arte moderno en Colombia. Vidales fue fundador de la revista Espiral junto a Clemente Airó, en 1944, en Bogotá. Destacamos en este párrafo el énfasis en la perplejidad y asombro del poeta que será fuente de inspiración y de método para el joven aprendiz de dibujante, de crítico literario y artístico y escritor, Clemente Airó, un republicano español que huyó del franquismo y se refugió en Colombia hasta su muerte en 1975.

Pablo Airó, hijo de Clemente, fotógrafo y estudioso de la vida de su padre nos refiere en estos términos su perfil:

“El escritor y crítico de arte Clemente Airó nació en Madrid, España el 14 de agosto de 1918. Murió en Bogotá, Colombia el 21 de junio de 1975. Desde su más temprana edad escribío cuentos y narraciones y, tambien, estudio dibujo y pintura en la academia de artes y oficios de San Fernando. Fue bachiller del instituto de segunda enseñanza Cardenal Cisneros de Madrid (1934). Inició sus estudios de medicina en la Universidad de Madrid, pero fueron interrumpidos por la guerra civil en la que ingresó como miliciano de la Cruz Roja, en el Quinto regimiento (oct 36). Una vez terminada la contienda y vencido el ejército republicano, pasó al sur de Francia donde fue prisionero politico en Argeles. Pasado un año, fue liberado y viajó a la República Dominicana y posteriormente se radicó definitivamente en Bogotá, Colombia (1941). Airó se licenció en Ciencias de la Educación, Filosofía y Letras. Fue catedrático de las universades Nacional de Colombia, La Salle y La Pedagógica, donde enseñó humanidades por varias décadas. Fue fundador de la Asociación de Escritores de Colombia en 1956, también presidente del Ateneo Español de la seccional colombiana de críticos de arte." (Airó 2018: 15).

Como lo refiere Pablo Airó, la labor multifacética de Airó lo llevó a fundar la editorial Espiral (especializada en literatura, crítica y estudios sociales), a ser catedrático de arte en universidades colombianas, a producir programas de radio sobre arte y ser un destacado curador y promotor de exposiciones de artes plásticas en la época. Todo esto diez años antes de la llegada a Colombia de la crítica argentina Marta Traba, quien ha sido siempre presentada como la pionera y fundadora de la crítica de arte moderna en el país. 
Desde los primeros números, Espiral marca crudamente la época de crisis que se vivía en el mundo. La guerra civil española es el primer espectro que recorre la época y a Espiral. El segundo acontecimiento es la lucha contra el fascismo en la segunda guerra mundial. El tercero es la crisis humanística de la posguerra. En el primer número de la revista, el artículo central corre a cargo de José Antonio Lizarazo, escritor influyente, -muy cercano al lider progresista colombianos Jorge Eliécer Gaitán-, quien años después escribiría una de las novelas prominentes sobre la Violencia ("El día del odio"). Espiral siempre insistirá en plantear interrogantes sobre el porvenir de la cultura en la crisis del humanismo de la posguerra, de allí por ejemplo la publicación de sendos artículos de Merleau Ponty y María Zambrano sobre el tema. Podría decirse que el artículo de Osorio Lizarazo le da el norte venidero a Espiral:

\begin{abstract}
"Jamás podría encontrarse un verdadero intelectual, con alguna rara excepción, en categoria directiva dentro de la incongruencia oficial: que estos cargos se destinan para los lectores hábiles o para los autores de un discurso de ocasión o de servilismo bajo la monstruosa mediocridad de los cuerpos legislativos a donde concurren, ávidos, los tráficantes de cédulas de identidad en manos rurales...la cultura colombiana se ha imaginado, como una fantasmagoría sobre cuatro o cinco nombres que iluminan el dombo clausurado de nuestro cielo, pero que brillaron quebrantando el ambiente o sustrayéndose a él: Caro y Cuervo, Ezequiel Uricoechea y Silva, Suárez y Vergara, unos tergiversados por la política, otros difamados por la malevolencia y otros ausentes del país para sustraerse a su atmósfera espiritual deprimente. Todos más o menos hostilizados en su tiempo y luego explotados casi comercialmente para crear la gran farsa de la cultura colombiana". Osorio Lizarazo (1944: 3).
\end{abstract}

Luis Vidales se refería también al contexto turbulento del mundo en su artículo "La estética de nuestro tiempo", publicado en el número dos de Espiral, en marzo de 1944:

“el pensador está en la obligación de saber orientarse en el caos y descubrir en medio de él, sin dejarse atraer por todos los elementos de dispersión que las grandes épocas comportan, las leyes esenciales cuyo vitalismo en la historia son garantía plena de orientación para comprender la significación real de la cultura de su tiempo y desentrañar su futuro". Más adelante en otro singular artículo, Vidales reflexionará sobre esta idea sin ceder a un condicionamiento ideológico para la poesía: "No te dejes seducir -Oh Ulises firme- por la sirena de la poesía social, en la que solo encontrarás el esqueleto del poema, pero no el poema. Todo en el universo es poesía, sin excepción posible, pero todo es preciso rellenarlo, -debes, es tu obligación- con carne de poesía, de modo que el esqueleto quede denajo y no expueso al sol, como un cadáver abandonado y reseco. En la llamada poesía social falta casi siempre la piel; falta la sangre; falta la respiración. La criatura poética ha huído. Solo queda la prosa de la razón, como una fea osamenta. Toda gran poesía es social, sin que pueda ser lo contrario". (Vidales 1948: 3).

\title{
II. BREVE MIRADA A LA REVISTA ESPIRAL
}

La revista Espiral tuvo secciones permanentes de literatura y artes plásticas, tanto en creación como en crítica, además de secciones de difusión del arte y la cultura 
en los siguientes temas: Reseñas de libros" enlazada con la editorial Espiral'; Canje de revistas; Redes de artistas e intelectuales; Música; Selección de programas radiales culturales de emisoras; Resumen de conferencias, charlas, obras de teatro, ballet, recitales de poesía; En reseñas de libros de poesía, literatura, arte y humanidades de editoriales colombianas ${ }^{3}$; Reseñas de libros de editoriales extranjeras ${ }^{4}$; Difusión de libros que se distribuían en librerías ${ }^{5}$; Concursos de cuento, poesía, novela y ensayo; Intercambio de artículos de otras revistas bogotanas ${ }^{6}$, colombianas y latinoamericanas ${ }^{7}$.

En cuanto a la parte plástica, Airó le dedicó un espacio amplio y constante en la revista, destacando las exposiciones individuales y colectivas que se hacían en Bogotá, en especial de los numerosos colaboradores de la revista que, a su vez eran reconocidos artistas plásticos. Uno de los artículos más memorables celebra la inauguración de la Galería de arte en 1948 en la Avenida Jiménez, número 561:

\footnotetext{
"Espiral saluda con fervor a "Galerías de arte" y desea con franqueza el pleno éxito de la importancia labor por las artes plásticas que viene a desarrollar, felicitando a sus gestores e iniciadores por la evidencia voluntad de trabajo y triunfo", Espiral, No 14, septiembre 1948, p 5. En los números posteriores se hace un seguimiento de las exposiciones, como la de Guillermo Silva: "su pintura se destaca por la clara expresión de los colores empleados con limpieza y manifiesta técnica orientada hacia el efecto impresionista de la pincelada. Su exposición se inauguró el 22 de noviembre último en las Galerías de Arte de Bogotá". (Airó 1948:17).
}

\footnotetext{
${ }^{2}$ Es fundamental el trabajo articulado entre la revista Espiral y la editorial Espiral. En la revista se reseñan permanentemente los libros que publica la editorial (incluyendo también a Iqueima) y hay anuncios de páginas completas del catálogo de la editorial y de los premios literarios que promovía la editorial.

${ }^{3}$ Algunas de ellas son Prensas de la Universidad Nacional, ABC de Bogotá, Biblioteca de autores nortesantandereanos, Ministerio de Educación Nacional, Ediciones Arte, librerías unidas de Barranquilla, Casa de la cultura de Medellín, Medusa de Popayán, Imprentas JGB de Cali, ediciones revista América, Editorial Santafé, Ediciones Librería suramericana, Antares, Kelly, Saturno de Bogotá

${ }^{4}$ Entre ellas están Aguilar, Editora nacional, Cronos, Estudios literarios de Zaragoza, Revista de Occidente, ínsula, Janés, Ediciones cultura hispánica, Adonais de España, Fondo de Cultura económica, Minerva, cuadernos americanos, Siglo, Océano, de México, Zigzag, Ercilla, multitud de Chile, Ayacucho, Lautaro, Lauro, Argos, Emecé, Futuro, Suramericana, Losada, Sur, Nova de Argentina, Casa de la cultura ecuatoriana, edición universitaria Loja, Cenit de Cuenca, de Ecuador, Cuadernos dominicanos de cultura, ediciones de Guatemala, Ayón de Cuba, ediciones ministerio de Educación, Cruz del sur, de Venezuela, Ediciones sociales, Nuevo mundo, Correa, Autour du monde, Gallimard de Francia, Hispanic Institut de Estados Unidos.

${ }^{5}$ Encontramos mencionadas: La Gran Colombia, Latina, Siglo XX, Librería colombiana, Librería el mensajero, en Bogotá o Voluntad de Medellín (vitales anunciantes de la revista).

${ }^{6}$ Desde el primer número se menciona el canje de revistas. La primera fue "Nuevo mundo" de Bogotá, revista indigenista dirigida por Miguel Adler, Discípulo de Paul Rivet.

${ }^{7}$ Por ejemplo Suplemento de las Españas, Jornadas del Colegio de México (artículo de Max Aub sobre Unamuno en el número 19 de diciembre de 1948), Papeles de Buenos Aires, dirigida por el hijo de Macedonio Fernández.
} 


\title{
III. ARTE EN DISENSO
}

En artículos, ponencias y conferencias de los últimos dos años ${ }^{8}$ en torno a nuestra investigación sobre la Revista Espiral de Bogotá (1944-1975), hemos insistido en que uno de nuestros hallazgos consiste en mostrar hasta qué punto la revista y editorial Espiral impulsada por el crítico y escritor Clemente Airó no constituye un "grupo" ni una "etiqueta" estética, ideológica o de generación. En esta oportunidad queremos preguntarnos por el rol del editor en los debates artísticos e ideológicos de la época que develan las profundas diferencias que circulaban entre los intelectuales de la época, lo cual controvierte las habituales clasificaciones sobre "hegemonías" o identidades de grupo (Los Bachue, los abstractos, etc.), difundidas sobre todo por Marta Traba.

La historia del arte, y en especial de la literatura, en América Latina y sobre todo en Colombia, suele clasificarse según generaciones y etiquetas de grupos o tendencias ideológicas y estéticas más o menos cerradas. En el caso colombiano, el período del medio siglo que corresponde al tiempo de la revista Espiral, se organizaría en literatura según la pugna aparente de las generaciones: de los grupos de "Centenaristas", "Nuevos", "Piedracielistas" y "Mito". En hora temprana mencionaba el poeta, traductor y crítico de poesía Andrés Holguín que dichas clasificaciones eran problemáticas y reductoras:

\begin{abstract}
"quizá no puede hablarse propiamente de un "grupo" formado por quienes cronológicamente han seguido a los poetas de "Piedra y cielo". Los poetas últimos no han formado una escuela, una capilla. No haberse agrupado estéticamente. No tener unos postulados comunes. Es haber desechado todo socialismo poético. Es no creer en la existencia de una clave, mágica y exclusiva que abra y cierre el mundo de la poesía...Al lado de Fernando Charry Lara que, recogido sobre sí mismo, dice su trémula nostalgia, aparece Eduardo Mendoza Varela que expresa la emoción de la ciudad cosmopolita y el vértigo del mecanismo en imágenes brillantes". (Holguín 1945: 20).
\end{abstract}

Con respecto a artes plásticas, en Espiral tienen una activa presencia tanto los consagrados pintores (a la vez compartiendo sus letras críticas) como Luis Alberto Acuña o Ignacio Gómez Jaramillo, así como los miembros de las rupturas más contemporáneas, ligadas al arte abstracto como Guillermo Wiedemann ${ }^{9} \mathrm{o}$ Marco Ospina ${ }^{10}$. Si repasamos el Consejo editorial del primer número de Espiral es evidente la pluralidad de su composición, lo que marcará el espíritu de la revista a lo largo de 31 años:

\footnotetext{
8 Conferencia sobre Airó. Instituto Caro y Cuervo, noviembre de 1017. https://www.youtube.com/watch?v=g-8K7oXaaos

${ }^{9}$ En el importante estudio sobre inmigrantes en el arte colombiano, se deja de lado la participación de Wiedemann en Espiral.

${ }^{10}$ En 1944, fecha en que inició su carrera de docente en la Universidad Nacional, Marco Ospina era integrante del consejo de redacción de Espiral. Revista de Artes y Letras, cuyo primer número salió a la luz en abril.
} 


\section{Primer Consejo de redacción de la Revista Espiral (1944)}

Luis Vidales; Eduardo Zalamea Borda; Hernando Téllez ${ }^{11}$; J. A Osorio Lizarazo

Marco Ospina; Arturo Camacho Ramírez; Ignacio Gómez Jaramillo; Luis B Ramos; Álvaro Pachón de la Torre; Octavio Amortegui; Luis Alberto Acuña

Álvaro Sanclemente; Roldán Castello; Clemente Airó

\section{Como lo señala otro destacado crítico extranjero radicado en Colombia:}

“La obra de Ignacio Gómez Jaramillo se nos presenta como un gran conjunto orgánico, que se encuentra en una evolución permanente, pero excluye las revoluciones ruidosas. Esta consonancia es el resultado de una fuerte personalidad que unifica todo por su escritura pictórica siempre generosa, siempre admirablemente segura de sí misma, una personalidad que representa uno de los más altos valores en el arte colombiano de este siglo". (Engel 1944: 3).

Otros investigadores como Carmen María Jaramillo ${ }^{12}$ ya han sugerido y estudiado que figuras críticas (extranjeros, una vez más, de allí nuestra insistencia en el exilio como punto de partida), como Walter Engel ${ }^{13}$ y Casimiro Eiger son mucho más que antecedentes de Traba ${ }^{14}$ y conforman una primera etapa de la crítica de arte moderno en Colombia. Sin embargo, la figura de Airó y Espiral, si bien son mencionados, -más bien marginalmente- no han tenido el lugar central que merecen y que pretendemos destacar. ${ }^{15}$

${ }^{11}$ Hay numerosas incógnitas por seguir elucidando en torno a la presencia de Airó y Espiral. Una de ellas tiene que ver con la aparición temprana de Téllez en el consejo de redacción y, sin embargo, no participar en ningún número y a lo largo de su obra, nunca referirse a Airó, como pudo comprobarse el año pasado en la publicación de los tres tomos de obra crítica de Téllez a cargo de Carlos Rincón en edición del Caro y Cuervo.

12 "Cabe anotar que antes de arribar Marta Traba a Colombia, críticos de arte como Luis Vidales, Casimiro Eiger, Clemente Airó, Walter Engel, Jorge Gaitán Duran y Juan Friede, entre otros, manifestaban una actitud valorativa matizada y un nivel calificado de interpretación sobre los trabajos, tanto de los artistas en mención como de la generación que habría de relevarlos. Esos críticos mantuvieron un diálogo estrecho con las diferentes propuestas artísticas de su época sin expresar reparos por la orientación plástica y mediante sus escritos contribuyeron a la definición de diferentes acepciones sobre la noción de modernidad de la época". Jaramillo, C. (1999: 40-41)

13 “Desde 1941 y hasta 1965, Engel dejó consignado en ensayos, breves notas, balances anuales y resúmenes el devenir del desarrollo artístico nacional en diversas revistas y periódicos: Revista de las indias, de 1941 a 1951; El Tiempo (Bogotá), de 1944 a 1955; revista Plástica (Bogotá), de 1956 a 1960; El Espectador (Bogotá), de 1960 a1965; El liberal y El Heraldo (Barranquilla); Espiral. Revista de Artes y Letras; Vida; Proa; Sábado; Panorama; Revista de América; Índice Cultural y Boletín Bibliográfico; Revista de la Universidad Nacional y Cromos". Jaramillo, J, (op cit: 71)

${ }^{14}$ En la década del sesenta se comenzó a advertir el desplazamiento de la noción de 'arte moderno' con respecto de la década anterior. Clemente Airó, presidente de la sección colombiana de la Asociación Internacional de Críticos de Arte (AICA) Y director de la 'Revista Espiral', afirmó que la expresión 'arte moderno' es "ya hoy aceptada - quizá con injusticia exclusivista - en cuanto se refiere tan sólo a la modalidad abstracta". (56-57) cita tomada de: Clemente Airó, "Ensayo. Análisis del arte Contemporáneo y sus influencias". Revista Espiral. Bogotá, junio de 1960, página 8. En, Jaramillo, C (2012: 40-41).

15 "El español Clemente Airó, director de la revista Espiral, hace únicamente apariciones esporádicas en el campo de la plástica, y el intelectual alemán Juan Friede, aunque incursiona 
Uno de los aspectos más significativos apunta a resaltar que en Espiral convivían artistas y críticos de "grupos" y "generaciones" diversas. Es esencial enfatizar que Jorge Jaramillo junto a Carmen Jaramillo es la crítica que más valora el trabajo de Airó:

\begin{abstract}
“Por ello, con desdén por los artistas academicistas, su juicio se orientó a valorar positivamente la obra de Alipio Jaramillo, Carlos Correa, Pedro Nel Gómez, Ramón Barba, Ignacio Gómez Jaramillo, Luis Alberto Acuña, Marco Ospina y, en los cincuenta, la de Alejandro Obregón y Lucy Tejada. Algunos artistas agrupados históricamente bajo la denominación de Los Bachué encontraron en la revista un lugar propicio para escribir como fue el caso de Luis Alberto Acuña, Carlos Correa e Ignacio Gómez Jaramillo- y también para divulgar sus obras, algunas de las cuales conocemos justamente por las imágenes publicadas en esta revista." (Jaramillo, J, op cit: 106).
\end{abstract}

Ahora bien, nuestro interés principal es preguntarnos cuál fue el rol de Clemente Airó como editor de Espiral y en un sentido más general preguntarnos por el rol de un editor. En el estudio de la revista constatamos que el papel de Airó va mucho más allá de tomar partido permanentemente por un autor, tema o situación: Airó propiciaba los debates, las controversias, que pueden verse por ejemplo en las encuestas ${ }^{16}$ a las que respondían los autores, así como en las disidencias entre los mismos. Podríamos decir, evocando a Rancière que uno de los aspectos más democráticos, plurales y diversos de Airó y de Espiral consistió justamente en propiciar el disenso:

\footnotetext{
"las artes no prestan nunca a las empresas de dominación o de la emancipación más que lo que ellas pueden prestarles, es decir, simplemente lo que tienen en común con ellas: posiciones y movimientos de cuerpos, funciones de la palabra, reparticiones de lo visible y de lo invisible. Y la autonomía de las que ellas pueden gozar o la subversión que ellas pueden atribuirse, descansan sobre la misma base". (Rancière 2009: 19).
}

Detengámonos en el concepto de "función de la palabra". Si comparamos dicha función en Marta Traba y en Airó, podemos rastrear varias diferencias esenciales sobre el rol de un editor. En Traba, su principal misión y el sentido mismo de su práctica como curadora, critica de arte y editora consistía en buena medida en "modernizar" el arte en Colombia y para ello solía trazar dos campos irreconciliables entre los que ella consideraba modernos y los que no. De esa forma, siguiendo a Rancière, podríamos decir que en Traba el mapa de lo visible estaba ya previamente establecido, por lo tanto su rol se dirigía a defender una posición, más que a interrogar otras posiciones divergentes. Su máxima meta era generar el consenso más amplio posible sobre su visión de modernidad. En

algunas veces en reflexiones sobre artistas jóvenes, se dedica principalmente a los pintores que están en su plenitud creativa y que poseen otros intereses plásticos. No obstante, quienes con criterios definidos y de una manera profesionalizada, se ocupan en mayor medida de los artistas que por ese momento comienzan a aparecer, son el alemán Walter Engel y el colombiano Luis Vidales". Jaramillo, C (1999: op cit, 19).

${ }^{16}$ Ejemplo de ello es la encuesta sobre Crítica promovida por Espiral en febrero y abril de 1957. 
revancha, en el caso de Airó, la selección de obras y autores de la revista sugiere otro tipo de posición, que llamaríamos más de disenso. Su propósito no era defender o alcanzar la "modernidad" en el arte colombiano, sino explorar miradas divergentes, heterodoxas sobre arte, más allá de un único concepto unificador. Por ello en sus críticas, curadurías y editoriales no traza una división entre dos tendencias, sino que acoge en sus intervenciones visiones heterodoxas sobre arte.

En 1969, cuando cumple la revista Espiral 25 años de labores, Airó organiza un dossier doble sobre "Artes plásticas en Colombia". En un largo y completo artículo de 20 páginas traza las coordenadas de una visión alternativa de la historia del arte moderno en Colombia y al precisar su posición, difiere por completo de la de Marta Traba, al señalar varias innovaciones simultáneas que ocurrían en Colombia desde los años treinta. Para Airó, más que dividir los artistas en grupos, se trataba de sugerir tensiones menos excluyentes de lo que parecía para Traba. Ese fue justamente el espíritu de Espiral. Más que una ruptura total entre generaciones, como lo definía Traba, el panorama plástico en Colombia, según Airó, respondía a contrapuntos que ya se insertaban en la emergencia de una idea de arte y crítica moderna, iniciadas desde los años cuarenta:

\footnotetext{
"cuando apareció la siguiente generación de pintores, hacia los años 50, levantose cierta animosidad contra los pioneros de la innovación. Indudablemente fue -lo comprendemos muy claro- la característica oposición de la juventud hacia sus maestros. Así se predicó que éstos habían sido desalojados de no se sabe bien qué trono, para ser reemplazados por más jóvenes y más buenos pintores. En realidad lo que ocurrió fue que llegaban a la palestra pintores salidos directamente de la corriente renovadora impuesta en Colombia mediante el trabajo de sus más inmediatos antecesores". (Airó 1969: 26).
}

La evidencia que da para ello Airó en su artículo es situar el paradigma moderno en 1944 con el V salón de arte, ya que:

\footnotetext{
"se presenta ya a la lid de una ampliación considerable de la pintura colombiana, que busca aceleradamente colocarse a la par de las corrientes artísticas de la segunda post guerra mundial. Aparecen nombre como Alejandro Obregón, Enrique Grau, Rodríguez Villamizar. Desde este V salón es indiscutible surgió cierta tensión entre los pintores que llevaron a cabo la innovación (Luis Alberto Acuña e Ignacio Gómez Jaramillo) y sus inmediatos seguidores. Hecho cuya lógica deviene de la dinámica de los estilos artísticos y también de la evolutiva imposición social. Pero las puertas que daban paso a la libre indagación habían sido ya abiertas." (Airó, op cit: 31).
}

Para complementar esta posición, se publica en el mismo dossier consistentes artículos de otros críticos extranjeros especializados en arte colombiano como Walter Engel y Galaor Carbonell. Para éste último, establecer divisiones excluyentes entre artistas y grupos (a la manera de Traba) es equivoco:

"es curioso que los dos grupos (figurativos/ no figurativos) se hayan mostrado generalmente antagónicos el uno con respecto del otro. Esta animosidad no tendría razón 
de ser si se entendiera que cada una de las actitudes señaladas está comprometida con funciones que de ningún modo pueden ser juzgadas de acuerdo con los objetivos que no les pertenecen. El antagonismo mencionado parecerá aún más ilógico si se comprende que las funciones respectivas de cada una de las tendencias son funciones complementarias, es decir, que las unas no pueden existir ni tienen razón de ser sin la presencia de las otras". (Carbonell 1969: 64).

Es importante anotar que Traba llega a Colombia en 1954, es decir, diez años después de este acontecimiento notable señalado por Airó. En otras palabras, el inicio de Espiral coincide con el V salón y acompaña Airó con su labor como crítico, galerista y curador la evolución del arte moderno en Colombia, una década antes de los aportes de Traba. Esta constatación nos permite señalar que Espiral y Airó no son meros antecedentes del arte y la crítica de arte en Colombia, sino protagonistas principales y testigos de primera mano de su emergencia.

Es por lo menos inquietante constatar como quedó sepultada esta actitud estética de Airó hasta nuestros días, debido a la preponderancia absoluta de Traba como "fundadora" de la crítica moderna de arte en Colombia. Nuestra hipótesis de trabajo define a Espiral y a Airó como exponentes del Disensos y a la revista Prisma y Traba como defensores de un nuevo consenso sobre arte moderno.

Para ejemplificar lo que señalamos, podemos ver múltiples documentos, en especial alrededor de la revista Prisma (fundada por Traba en 1957), pero detengámonos para nuestro propósito en el dossier sobre arte en Colombia dirigido por Traba en el número 689 de la revista Semana (17 de marzo de 1960), en el que la crítica plantea de manera directa dicha división:

“dentro de la etapa de transición, cuyos integrantes actúan entre los años veinte y cuarenta, la pintura colombiana (al lado de la cual comienza a levantarse, muy penosamente una escultura nacional) conoce y digiere varias influencias del arte europeo contemporáneo: el puntillismo, a través de la obra de Luis Alberto Acuña; la geometría cezanniana de las formas a través de Ignacio Gómez Jaramillo; el expresionismo español de Gutiérrez Solana a través de Carlos Correa. Por otra parte, la gran influencia, asimilada entusiastamente por todo el grupo de transición, está constituida por el muralismo mexicano, entonces en pleno furor bélico. Más que técnica o formal, la influencia mexicanista es de tipo ético, ya que incita a los artistas a cumplir con sus obligaciones ciudadanas por medio de la pintura, o en otras palabras, a ejecutar arte-testimonio que demuestre su preocupación por los problemas económicos-sociales de sus respectivos países". (Traba 1960: 9).

¡Que gran paradoja enfrentaban los artistas de "transición"! Traba los reduce a hacer arte-testimonio, y otro crítico esencial de la época, fundador de Espiral, Luis Vidales ${ }^{17}$, los acusa de lo contrario, de no ser suficientemente

\footnotetext{
${ }^{17}$ Esta es la defensa de Gómez Jaramillo (por el momento no hemos podido ubicar la crítica de Vidales a la que hace alusión): “Y yo me pregunto, frente a la crítica del señor Luis Vidales, ¿cuál ha sido su obra revolucionaria? ¿cuál ha sido su mensaje social? ¿cuál ha sido su labor en beneficio del pueblo? ¿cuál ha sido la creación que lo ha consagrado en el país y fuera de él como valor indiscutible que le dé autoridad suficiente para convertirse en implacable censor, en inquisidor
} 
políticos y sociales. Justamente los pintores de "transición" citados por Traba constituyen el (medio) centro de Espiral. Lo paradójico es que el otro centro de Espiral lo conforman los artistas promovidos por Traba. Es por ello que vemos en Espiral una política del disenso. Espiral no opone un canon a otro. Retomando el texto de Traba vemos que:

“La pintura, capitaneada por Obregón, recupera rápidamente posiciones: mientras Obregón cultiva un expresionismo figurativo que se complace en darle calidad, fuerza y sentimiento al color...en los últimos años se han perfilado claramente en Colombia las dos tendencias que hoy se disputan la hegemonía en el panorama del arte universal: el abstraccionismo y el expresionismo figurativo. Los pintores más notables dentro de la primera tendencia son: Eduardo Ramírez Villamizar, quien elabora formas geométricas tendientes a alcanzar dentro de lo abstracto, un nuevo "clasicismo". Guillermo Wiedemann, nacido en Alemania y nacionalizado en Colombia, cuya actual obra abstracta es anti-geométrica en la forma y romántica en el fondo... Afiliados con mayor pasividad a la innumerable lista de pintores modernos que no se deciden a abandonar la realidad ni se atreven a alterarla excesivamente, ni se resignan a escapar totalmente de las leyes estéticas de su tiempo, figuran también en las exposiciones artistas como Grau, Lucy Tejada, Cecilia Porras y algunos otros". (Traba op cit: 10).

\section{A MANERA DE CONCLUSIÓN}

Como se ha dicho, los pintores "modernos" de Traba también componen la otra mitad del círculo de Espiral (Obregón, Wiedemann, Tejada, Grau, Porras). Vemos en esta composición diversa, la mirada y el rol de mediador de disensos de Airó (como podemos constatarlo en sus editoriales), a diferencia de la postura homogeneizante de Traba. En las últimas décadas, sobre todo a partir de la recuperación de la obra y el método de Aby Warburg, las clasificaciones de historia del arte cerradas, excluyentes y tajantes han sido por completo socavadas y reinventadas, en privilegio de diálogos y disonancias cada vez más paradójicas. Como lo propone Didi Huberman: “el historiador de arte encuentra imágenes dialécticas, da cuenta de ellas, produce nuevas" (Didi Huberman 2010: 121).

Esto significa que Espiral y Airó constituyen un eslabón perdido de una historia alternativa del arte en Colombia, más orientada a la heterodoxia que a las etiquetas fijas. De allí quizá la invisibilidad de su contribución a la crítica de arte en Colombia ${ }^{18}$. Airó y Espiral no eran una trinchera de los Bachué frente a los modernos. No le dieron la espalda a la emergencia de otros lenguajes, encaminados a lo abstracto y a lo no-figurativo. Nuestra pregunta inicial se encamina entonces a otros interrogantes paralelos: ¿la labor de un

de ideas, en director estético y en líder revolucionario? ¿"suenan timbres"? ¿el tratado de estética? ¿su libro sobre el 9 de abril? ¿o su famosa huelga de hambre?". (Gómez Jaramillo 1987: 221).

${ }^{18}$ Como lo hemos mostrado en otros espacios, si bien se menciona a Espiral y a Airó en estudios especializados, nunca se le ha dedicado un trabajo monográfico completo. Por ejemplo, Nicolás Gómez en su artículo, "una voz para el arte", sobre el salón de arte de 1957, se concentra en las revistas Prisma y Plástica. 
editor/crítico/curador consiste en "unificar" autores, obras y temáticas, o más bien en generar espacios de disensos que profundicen matices, diferencias, divergencias? ¿La posición hegemónica de Traba, sin desconocer de ninguna manera su aporte a las artes en Colombia, no fue acaso contraproducente para la consolidación de una historia del arte más problematizada? En ese sentido, nos gustaría sugerir para finalizar que la figura de Airó y Espiral representan una posibilidad latente de cartografiar una contra-historia del arte en Colombia que se construye a través de paradigmas diferentes a los de Traba.

Lo complejo de la posición de Traba radica en definir como meros antecedentes de modernidad, la pintura del grupo "Bachue", algo que primó en catálogos, exposiciones y estudios críticos hasta tiempos recientes. Recién, en los últimos años, ha ido reapareciendo la obra de estos pintores, condenados por Traba al ostracismo.

\section{BIBLIOGRAFÍA}

AIRÓ, Cl. (1948), “Galerías de arte”, Espiral, 19, diciembre de 1948, 14-18.

AIRÓ, Cl., (1969), “Los años de la innovación pictórica”, Espiral, 111-112, septiembre de 1969, 90-105.

AIRÓ, Cl., (1952), “Plástico trópico negro, el pintor Wiedemann”, Espiral, 42, octubre 52, 24-28.

AIRÓ, P. (2018), Biografía de Clemente Airó, Archivo Pablo Airó, Canada.

BejARANO, A. (2017), "La utopía en la revista Espiral de Clemente Airó", Revista Nómadas, 47, 97-106. Disponible en:

$<$ http://nomadas.ucentral.edu.co/index.php/inicio/2368-utopias-entre-lo-posibley-lo-probable-nomadas-47/2-heroes-y-villanos/933-la-utopia-en-la-revista-

bogotana-espiral-1944-1975-de-clemente-airo>.

CARBONELL, G. (1969), “Los años sesentaytantos, la pintura actual”, Espiral, 111-112, septiembre de 1969, 46-54.

Didi Huberman, G. (2010), Lo que vemos, lo que nos mira, Manantial, Buenos Aires.

ENGEL, W. (1944), “La obra de Gómez Jaramillo", Espiral, 3, junio de 1944, 5-9.

ENGEL, W. (1949), “Wiedemann”, Espiral, 22, junio 49, 14-18.

GÓMEZ JARAMILLO, I. (1987), “Gómez Jaramillo responde a Luis Vidales”, en Anotaciones de un pintor, Gómez Jaramillo, I., ediciones autores antioqueños, Medellín, 219-221.

GómEZ, N. (2007), “Una voz para el arte”, en Salón de arte moderno 1957, Suarez, S. (ed.), Banco de la República, Bogotá, 122-148.

Holguín, A. (1945), "Retorno de la poesía”, Espiral, 11, junio de 1945, 28-38.

JARAMILlO, C. M. (1999), Informe final de la Beca de investigación en artes plásticas, Ministerio de Cultura, Bogotá.

JARAMILlO, C. M. (2012), Fisuras del arte moderno en Colombia, Alcaldía Mayor, Bogotá.

JARAMILlO, C. M. (2013), Inmigrantes. Artistas, arquitectos, fotógrafos, críticos y galeristas en el arte colombiano. 1930-1970, Alcaldía de Bogotá, Bogotá.

OSORIO LIZARAZO, J. A. (1944), “Existe una cultura nacional?”, Espiral, 1, abril de 1944, 1-3.

RANCIÈRE, J. (2009), El reparto de lo sensible, Lom editores, Santiago de Chile. 
TRABA, M. (1960), “Trayectoria del arte colombiano", Revista Semana, 689, marzo de 1960, 69-86.

VIDALES, L. (1948), “Advertencias a un joven poeta”, Espiral, 17, octubre de 1948, 12-17.

VIDALES, L. (1986), “Confesiones de un aprendiz del siglo", en Suenan timbres, Vidales, L., Plaza y Janes, Bogotá, 6-29.

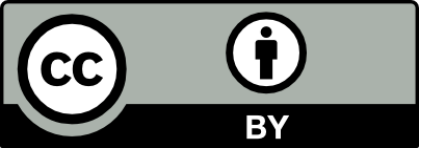

Llevat que s'hi indiqui el contrari, els continguts d'aquesta revista estan subjectes a la llicència de Creative Commons: Reconeixement 3.0 Espanya. 